\title{
Treatment of Secondary Immune Mediated Hemolytic Anaemia of Dogs in Chennai, Tamil Nadu
}

\author{
Chopel G. Lachungpa ${ }^{1}$, D. Chandrasekaran ${ }^{2 *}$, M.B. Thilagar ${ }^{3}$ and T.M.A Senthil Kumar ${ }^{4}$ \\ ${ }^{1}$ Department of Veterinary Clinical Medicine, Madras Veterinary College, Tamil Nadu Veterinary and Animal Sciences \\ University, Chennai, Tamil Nadu, INDIA \\ ${ }^{2}$ Department of Clinics, Madras Veterinary College, Tamil Nadu Veterinary and Animal Sciences University, Chennai, \\ Tamil Nadu, INDIA \\ ${ }^{3}$ Department of Veterinary Clinical Medicine, Madras Veterinary College, Tamil Nadu Veterinary and Animal Sciences \\ University, Chennai, Tamil Nadu, INDIA \\ ${ }^{4}$ Department of Animal Biotechnology, Madras Veterinary College, Tamil Nadu Veterinary and Animal Sciences University, \\ Chennai, Tamil Nadu, INDIA \\ "Corresponding author: D Chandrasekaran; E-mail: drchandrus73@gmail.com
}

Received: 04 June, 2020

Revised: 14 July, 2020

Accepted: 26 July, 2020

\begin{abstract}
Immune-mediated hemolytic anemia (IMHA) is the most common autoimmune disease in dogs. This study was conducted to evaluate prednisolone and azathioprine therapeutic protocols for the management of secondary IMHA in dogs. The anaemic dogs brought with clinical signs such as pale or icteric mucous membranes were screened for IMHA by saline agglutination and spherocyte count and confirmed by flow cytometry. The positive cases were further subjected to haematology, biochemistry, coagulation profile, MAT and polymerase chain reaction (PCR) for the diagnosis of underlying secondary causes like Babesia spp, Ehrlichia canis and Leptospira spp (secondary IMHA). Thirty two cases were positive for IMHA, out of which thirteen cases were primary (Idiopathic) IMHA (17.3\%) and remaining nineteen cases were secondary IMHA $(82.7 \%)$ due to underlying causes such as Babesia gibsoni (13), Ehrlichia canis (3) and Leptospira spp. (3) respectively. Immunosuppressive therapy with prednisolone and prednisolone in combination with azathioprine and specific therapy of etiological agent with supportive therapy was used. Significant increase in $\mathrm{Hb}, \mathrm{PCV}, \mathrm{RBC}$ and thrombocyte count, significant decrease in leucocyte, neutrophil, monocyte and total protein and significant increase in ALT activity was recorded after therapy. There was an apparent clinical improvement in all the dogs which survived till day 28 days, with significant improvement in hemato-biochemical profiles. Prednisolone was found to be effective in the management of canine secondary IMHA than prednisolone combined with azathioprine.
\end{abstract}

\section{HIGHLIGHTS}

(o Secondary Immune mediated hemolytic anemia - Immunosuppressive therapy - Prednisolone, Prednisolone + Azathioprine.

(0 Prenisolone - Effective in management of canine secondary IMHA.

Keywords: Dog, Secondary IMHA, Treatment, Prednisolone, Azathioprine

Immune-mediated haemolytic anaemia (IMHA) was a type II hypersensitivity reaction in which antibodies (mainly IgG and IgM) were produced against normal RBCs (primary IMHA) or against RBCs in which surface antigens were altered through interaction with secondary causes such as drugs, infectious diseases and neoplasia (secondary IMHA) (McAlees, 2010).
Secondary IMHA is caused by an immunologic response to nonself antigens that have modified or are associated

How to cite this article: Lachungpa, C.G., Chandrasekaran, D., Thilagar, M.B. and Senthil Kumar T.M.A (2020). Treatment of secondary immune mediated hemolytic anaemia of dogs in Chennai, Tamil Nadu. J. Anim. Res., 10(4): 535-541.

Source of Support: None; Conflict of Interest: None 
with normal RBC membranes. Secondary IMHA can be caused by a number of underlying processes. Affected RBCs may become infected by pathogens or coated with foreign antigen. Documented or hypothesized causes of secondary IMHA include bacterial, viral, rickettsial, parasitic, protozoan and neoplastic disorders (Giger, 2005).

Immunomodulation is the mainstay of treatment of IMHA, with the aim of decreasing erythrophagocytosis and suppressing immunoglobulin production and can be combined with whole blood or packed red cell transfusions and anticoagulation (Balch and Mackin, 2007).

McCullough (2003) and Weinkle et al. (2005) reported that prednisone typically dosed @ $2 \mathrm{mg} / \mathrm{kg}$ PO q12-24h, once remission had been maintained for 1 to 2 weeks, and then the dose could be reduced by 25 to 50 per cent every 2 to 4 weeks. Treatment could generally be stopped once the dose had been reduced to 0.25 to $0.5 \mathrm{mg} / \mathrm{kg}$ PO q $48 \mathrm{~h}$.

McCullough (2003) reported azathioprine used in dogs at a dose of $2 \mathrm{mg} / \mathrm{kg}$ PO q24h. The dose was often given on alternate days when prednisone therapy was decreased to every other day. Balch and Mackin (2007) reported that azathioprine, a purine analogue anti metabolite that preferentially suppresses T-cell function, frequently used as an additional immunosuppressive agent in dogs with severe IMHA.

Hence, the present study was undertaken with the objective to evaluate prednisolone and azathioprine therapeutic protocols for the management of secondary IMHA in dogs.

\section{MATERIALS AND METHODS}

\section{Selection of animals and sampling}

Seventy five anemic dogs were presented to the Small Animals Out-Patient Unit of Madras Veterinary teaching Hospital and Critical Care Unit of the Department of Veterinary Clinical Medicine, Madras Veterinary College, Chennai during a period of 1 year from July 2016 to June 2017. An individual history of those dogs with pale or icteric mucous membranes were screened for IMHA by saline agglutination test, spherocyte count and confirmed by flow cytometry.

Thirty-two dogs positive by flow cytometry were selected for the study. The saline agglutination test was performed by mixing a drop of whole blood collected in EDTA vacutainer with drop of saline on a glass slide. Microscopic agglutination test was performed with a saline dilution on a glass slide (one drop of blood to two drops of saline) and inspected under light microscope. The positive result was manifested by clumping of red blood cells (Balch and Mackin, 2007). An air dried thin blood smear was made from capillary blood obtained from the anterior edge of the hairless ventral surface of the ear, stained with Leishman-Giemsa stain and examined microscopically for Babesia species and Ehrlichia canis organism, differential leucocyte count, spherocyte count and blood picture analysis.

\section{Flow cytometer}

Whole blood samples were analyzed by a flow cytometer as per the procedure of Kucinskiene et al. (2005). The IMHA flurochrome stained RBCs were acquired using MoFlow XDP flowcytometery (Beckman Coulter, USA) and data were analyzed using the summit software.

\section{Multiplex polymerase chain reaction (PCR)}

DNA isolation kit (QIAamp DNA Mini Kit ${ }^{\circledR}$, Qiagen) was used for the extraction of parasite DNA from $200 \mu \mathrm{l}$ of blood collected in EDTA vacutainers according to the manufacturer's instructions. Genomic DNA isolated from the whole blood of healthy dog was used as a negative control.

Multiplex PCR for the amplification of the 16s rRNA gene fragment of molecular length $619 \mathrm{bp}$ in genus Babesia and VirB9 of E. canis with a molecular length $380 \mathrm{bp}$ was employed following the procedure of Kledmanee et al., (2009).Nested PCR for the amplification of the $16 \mathrm{~s}$ rRNA gene fragment of $E$. canis was employed following the procedure of Rajagopal et al. (2009). Thermocycling consisted of initial denaturation step of $15 \mathrm{~min}$ at $94^{\circ} \mathrm{C}$ followed by 30 cycles of $45 \mathrm{sec}$ at $94^{\circ} \mathrm{C}, 45 \mathrm{sec}$ at $65^{\circ} \mathrm{C}$, and $90 \mathrm{sec}$ at $72^{\circ} \mathrm{C}$ with a final extension step of $10 \mathrm{~min}$ at $72^{\circ} \mathrm{C}$. The amplicons were separated by electrophoresis in $1.5 \%$ agarose gel in $40 \mathrm{mM}$ Tris-acetic acetate of $\mathrm{pH} 8.4$, $1 \mathrm{mM}$ EDTA, stained with ethidium bromide $(0.5 \mu \mathrm{g} / \mathrm{ml})$ and visualized under UV light. 


\section{Microscopic agglutination test (MAT)}

A battery of live leptospira serovars (L. australis, $L$. autumnalis, L. ballum, L. bataviae, L. canicola, $L$. grippotyphosa, L. hebdomadis,L. icterohaemorrhagiae, $L$. javanica, L. pomona and L. pyrogenes) were employed. The antigen antibody reaction / agglutination observed at $>1: 200$ serum dilutions were considered positive.

Positive samples for hemoprotozoan parasite like Babesia spp and Ehrlichia spp screened by multiplex PCR and leptospirosis by MAT were included for the study. The results are expressed as mean \pm SE. Data are classified with descriptive statistics and $\mathrm{P}$ values $<0.05$ are considered statistically significant. Data analysis was performed with the SPSS 20.

\section{TREATMENT PROTOCOL}

Two groups viz. I and II were formed with each group comprising of 7 and 6 dogs of different breed, either sex and varying age. The drugs indicated for secondary IMHA (Babesia gibsoni) were given in different combination in two groups. In Group I ( $\mathrm{n}=7)$, treatment of underlying causes with prednisolone. Combination therapy with clindamycin (Bioclan, Savavet, Sava healthcare Ltd. 25 mg, $150 \mathrm{mg}$ and $300 \mathrm{mg}$ )@ $25 \mathrm{mg} / \mathrm{kg}$ body weight per os BID, metronidazole (Flagyl, AHPL, India, 200 mg and 400 mg)@15/kg body weight per os BID and doxycycline (Doxypet, Savavet, Sava healthcare Ltd., 200 $\mathrm{mg}$ )@ $5 \mathrm{mg} / \mathrm{kg}$ body weight per os. BID for 28 days as per Suzuki et al. (2007). Prednisolone was given at the rate of $2 \mathrm{mg} / \mathrm{kg}$ body weight I/M or per os BID for 5 days followed by $1 \mathrm{mg} / \mathrm{kg}$ body weight per os BID for next 5 days per os. The drug was tapered to $0.5 \mathrm{mg} / \mathrm{kg}$ body weight per os SID for next 5 days. Whereas in Group II $(n=6)$, treatment of underlying causes with Prednisolone + Azathioprine. Combination therapy with clindamycin @ 25 mg / kg body weight per os BID, metronidazole@15 / kg body weight per os BID and doxycycline@10 mg / $\mathrm{kg}$ body weight per os BID for 28 days as per Suzuki et al. (2007). Azathioprine @ $1 \mathrm{mg} / \mathrm{kg}$ body weight per os BID for first 5 days followed by $0.5 \mathrm{mg} / \mathrm{kg}$ body weight per os BID for next 5 days. The drug was tapered to $0.5 \mathrm{mg} / \mathrm{kg}$ body weight per os BID for another 5 days. Prednisolone (a) $2 \mathrm{mg} / \mathrm{kg}$ body weight per os BID for 5 days followed by $1 \mathrm{mg} / \mathrm{kg}$ body weight per os BID for next 5 days. The drug was tapered to $0.5 \mathrm{mg} / \mathrm{kg}$ body weight per os SID for another 5 days.

\section{Supportive therapy}

The dogs with PCV less than 10 per cent or those dogs hemodynamically unstable were given fresh whole blood transfusion@12-20 ml/kg body weight. The dogs were administered with multiple electrolytes, dextrose injection and lactated ringer's solution@10ml/kg body weight. The dog with anemia $(\mathrm{PCV}<20$ per cent) were prescribed oral haematinics (aRBC syrup) and Thrombup syrup. Dogs with vomiting were injected with inj. Ondanseteron I/V (Emeset, 2 ml, Cipla Pharma Ltd.) @ 0.05 mg/kg body weight and inj. Ranitidine (Ultidec, SPM drug Pvt. Ltd.) (a) $1 \mathrm{mg} / \mathrm{kg} \mathrm{I} / \mathrm{M}$ for 3-5 days.

\section{Post treatment assessment}

Post treatment assessment was carried out after $14^{\text {th }}$ and $28^{\text {th }}$ day post treatment, based on haematological, biochemical and coagulation parameters and clinical improvement. Whole blood and serum samples were collected on before treatment on 0 day and post treatment assessment was done after $14^{\text {th }}$ day and $28^{\text {th }}$ day based on haematological, biochemical and coagulation parameters and clinical improvement.

\section{RESULTS AND DISCUSSION}

Haematological, biochemical and coagulation parameters were recorded before treatment ( 0 day) and after treatment viz., $14^{\text {th }}$ day and $28^{\text {th }}$ day in secondary IMHA. The quantitative data were subjected to One-Way Anova and independent sample t-test.

In thirteen secondary IMHA dogs, seven dogs received immunosuppressive dose of prednisolone (P Protocol) and six dogs received prednisolone combined with azathioprine (AP Protocol). In secondary IMHA, dogs treated with prednisolone, there was apparent clinical recovery on day $14^{\text {th }}$ and $28^{\text {th }}$ day after initiation of treatment. In all the dogs which survived, there was a significant increase in the means of $\mathrm{Hb}, \mathrm{RBC}, \mathrm{PCV}, \mathrm{MCHC}$ and platelets and decrease in mean WBC and mean neutrophil (Table 1 and $2)$. But there was no significant difference in means of $\mathrm{MCV}, \mathrm{MCH}$, lymphocyte, monocyte, eosinophil, PT and APTT.

Mean activity levels of ALT, total bilirubin and direct bilirubin were significantly reduced on $14^{\text {th }}$ and $28^{\text {th }}$ day after treatment with prednisolone. Mean of glucose was 
Table 1: Effect of different treatments on haemogram in secondary IMHA $(n=13)$

\begin{tabular}{|c|c|c|c|c|c|c|c|c|}
\hline \multirow{2}{*}{ Parameters } & \multicolumn{4}{|c|}{ Prednisolone $(n=7)$} & \multicolumn{4}{|c|}{ Prednisolone + Azathioprine $(n=6)$} \\
\hline & Day 0 & $14^{\text {th }}$ day & $28^{\text {th }}$ day & F-Value & Day 0 & $14^{\text {th }}$ day & $28^{\text {th }}$ day & F-Value \\
\hline $\mathrm{Hb}(\mathrm{g} / \mathrm{dL})$ & $4.14 \pm 0.66^{\mathrm{a}}$ & $8.98 \pm 0.99^{b}$ & $12.02 \pm 0.31^{\mathrm{c}}$ & $28.43^{* *}$ & $4.30 \pm 0.50^{\mathrm{a}}$ & $6.18 \pm 0.82^{\mathrm{a}}$ & $8.53 \pm 0.35^{b}$ & $7.67^{* *}$ \\
\hline $\mathrm{RBC}(\mathrm{mill} / \mu \mathrm{L})$ & $3.29 \pm 0.97^{\mathrm{a}}$ & $4.80 \pm 0.58^{\mathrm{a}}$ & $6.80 \pm 0.85^{\mathrm{b}}$ & $15.93 * *$ & $2.29 \pm 0.23^{\mathrm{a}}$ & $2.03 \pm 0.29^{\mathrm{a}}$ & $5.36 \pm 0.48^{b}$ & $0.79 *$ \\
\hline $\operatorname{HCT}(\%)$ & $13.55 \pm 3.21^{\mathrm{a}}$ & $28.15 \pm 3.04^{b}$ & $35.76 \pm 0.89^{b}$ & $23.76^{* *}$ & $19.08 \pm 1.13$ & $22.33 \pm 4.56$ & $26.60 \pm 5.80$ & $3.93 \mathrm{NS}$ \\
\hline $\mathrm{MCV}(\mathrm{fL})$ & $66.57 \pm 3.02$ & $59.87 \pm 5.57$ & $69.61 \pm 8.22$ & $0.78 \mathrm{NS}$ & $58.87 \pm 3.44$ & $53.45 \pm 2.90$ & $43.61 \pm 13.78$ & $1.59 \mathrm{NS}$ \\
\hline $\mathrm{MCHC}(\mathrm{g} / \mathrm{dL})$ & $30.37 \pm 0.54^{\mathrm{a}}$ & $32.01 \pm 0.75^{\mathrm{ab}}$ & $33.66 \pm 0.93^{b}$ & $5.11 *$ & $22.99 \pm 3.18$ & $31.48 \pm 4.94$ & $3634 \pm 9.86$ & $1.53^{\mathrm{NS}}$ \\
\hline $\mathrm{MCH}(\mathrm{pg})$ & $20.18 \pm 0.83$ & $18.98 \pm 1.32$ & $23.19 \pm 2.23$ & $2.07 \mathrm{NS}$ & $13.67 \pm 2.27$ & $16.94 \pm 3.11$ & $19.16 \pm 1.90$ & $0.55^{\mathrm{NS}}$ \\
\hline
\end{tabular}

Mean bearing same manuscript in the row do not differ significantly; ** - Statistically highly significant $(\mathrm{P} \leq 0.01)$ * Statisticallysignificant $(\mathrm{P}>0.05)^{\mathrm{NS}}-$ Non significant.

Table 2: Effect of different treatments on leucogram and coagulation profile in secondary IMHA (Babesia gibsoni) $(\mathrm{n}=13)$

\begin{tabular}{|c|c|c|c|c|c|c|c|c|}
\hline \multirow{2}{*}{ Parameters } & \multicolumn{4}{|c|}{ Prednisolone $(n=7)$} & \multicolumn{4}{|c|}{ Prednisolone + Azathioprine $(n=6)$} \\
\hline & Day 0 & $14^{\text {th }}$ day & $28^{\text {th }}$ day & F-Value & Day 0 & $14^{\text {th }}$ day & $28^{\text {th }}$ day & F-Value \\
\hline $\mathrm{WBC}(/ \mu \mathrm{L})$ & $\begin{array}{l}21671.43 \pm \\
3416.11^{\mathrm{a}}\end{array}$ & $\begin{array}{l}11983.33 \pm \\
1443.70^{\mathrm{b}}\end{array}$ & $\begin{array}{l}8520 \pm \\
1243.14^{b}\end{array}$ & $7.39 * *$ & $\begin{array}{l}21033.33 \pm \\
3402.02\end{array}$ & $\begin{array}{l}15666.67 \pm \\
2654.13\end{array}$ & $\begin{array}{l}12333.33 \pm \\
881.91\end{array}$ & $1.84 * *$ \\
\hline Neutrophil (\%) & $84 \pm 1.90^{\mathrm{a}}$ & $78.33 \pm 2.70^{b}$ & $73.60 \pm 0.98^{b}$ & $6.07 *$ & $73.67 \pm 0.84^{\mathrm{a}}$ & $77.83 \pm 0.71^{b}$ & $73.67 \pm 1.45^{\mathrm{a}}$ & $4.88^{*}$ \\
\hline Lymphocyte (\%) & $12.57 \pm 1.67$ & $17.17 \pm 1.44$ & $16.80 \pm 1.44$ & $2.85^{\mathrm{NS}}$ & $16.33 \pm 0.71$ & $15.33 \pm 1.47$ & $17.67 \pm 1.76$ & $0.66^{\mathrm{NS}}$ \\
\hline Monocyte (\%) & $4.14 \pm 0.26$ & $4.33 \pm 0.55$ & $4.20 \pm 0.66$ & $0.43^{\mathrm{NS}}$ & $8.33 \pm 1.08$ & $6.67 \pm 1.08$ & $5 \pm 00$ & $1.91 \mathrm{NS}$ \\
\hline Eosinophil (\%) & $0.57 \pm 0.36$ & $0.17 \pm 0.16$ & $0.20 \pm 0.20$ & $0.66^{\mathrm{NS}}$ & $1.50 \pm 0.34$ & $1.40 \pm 0.40$ & $0.67 \pm 0.33$ & $1.11^{\mathrm{NS}}$ \\
\hline $\begin{array}{l}\text { Platelet }\left(10^{3} /\right. \\
\mathrm{cmm})\end{array}$ & $\begin{array}{l}50142.86 \pm \\
6688.40^{\mathrm{a}}\end{array}$ & $\begin{array}{l}131566.67 \pm \\
2258.80^{\mathrm{b}}\end{array}$ & $\begin{array}{l}249800 \pm \\
36295.17^{c}\end{array}$ & $20.23 * *$ & $\begin{array}{l}71166.67 \pm \\
12365.04^{\mathrm{a}}\end{array}$ & $\begin{array}{l}123333.33 \pm \\
18282.35^{\mathrm{ab}}\end{array}$ & $\begin{array}{l}186333.33 \pm \\
14497.21^{\mathrm{b}}\end{array}$ & $10.28^{* *}$ \\
\hline PT (sec) & $40.43 \pm 10.07$ & $19.33 \pm 2.82$ & $17.20 \pm 5.43$ & $2.58^{\mathrm{NS}}$ & $41.33 \pm 1.96^{\mathrm{a}}$ & $18.0 \pm 2.3^{\mathrm{b}}$ & $10 \pm 1.0^{c}$ & $53.49 * *$ \\
\hline APTT(sec) & $42.74 \pm 7.57$ & $29.33 \pm 5.30$ & $18.80 \pm 2.41$ & $3.05^{\mathrm{NS}}$ & $61.91 \pm 13.51$ & $38.83 \pm 7.58^{a}$ & $17.00 \pm 3.00$ & $3.5^{\mathrm{NS}}$ \\
\hline
\end{tabular}

Mean bearing same manuscript in the row do not differ significantly; ** - Statistically highly significant $(\mathrm{P} \leq 0.01) *$ - Statisticallysignificant $(\mathrm{P}>0.05) \mathrm{NS}-$ Non significant.

increased on $28^{\text {th }}$ day after treatment with prednisolone. However, there was no significant difference in means of BUN, creatinine, total protein, albumin, globulin, A:G ratio and ALP activity.

In prednisolone and azathioprine combined treatment group there was a significant increase in the means of $\mathrm{Hb}, \mathrm{RBC}$ and platelet. There was a significant decrease in mean of WBC, neutrophil and PT and Blood urea nitrogen (BUN) post treatment. But there was no significant difference in means of $\mathrm{MCV}, \mathrm{MCH}, \mathrm{MCHC}$, lymphocyte, monocyte, and eosinophil and APTT. However, there was significantly increased activities of ALP and ALT after treatment (Table 3).

Mean of Blood urea nitrogen (BUN) was significantly reduced on $14^{\text {th }}$ and $28^{\text {th }}$ day after treatment with prednisolone and azathioprine combination. There was significant increase in mean activity levels of ALT and
ALP but there was no significance difference in means of total bilirubin, direct bilirubin, creatinine, total protein, albumin, globulin and $\mathrm{A}: \mathrm{G}$ ratio.

When compared between treatments of prednisolone group ( $\mathrm{P}$ protocol) and prednisolone combination with azathioprine group (AP Protocol) on $14^{\text {th }}$ and $28^{\text {th }}$ day after treatment as shown in Table 4, Table 5 and Table 6 . The mean of $\mathrm{Hb}$ and $\mathrm{RBC}$ on $28^{\text {th }}$ day was significantly higher and eosinophil on $14^{\text {th }}$ day was significantly lower in the group of dogs treated with prednisolone when compared to prednisolone+ azathioprine group. The means of remaining haematological and coagulation parameter were not significant.

Balch and Mackin (2007) reported prednisone single-agent glucocorticoid therapy were the mainstay and first line of treatment for IMHA for many patients and effective. The improvement might be due to reduced erythrophagocytosis 
Table 3: Effect of different treatments on serum biochemistry in secondary IMHA (Babesia gibsoni) ( $\mathrm{n}=13$ )

\begin{tabular}{|c|c|c|c|c|c|c|c|c|}
\hline \multirow{2}{*}{ Parameters } & \multicolumn{4}{|c|}{ Prednisolone $(n=7)$} & \multicolumn{4}{|c|}{ Prednisolone + Azathioprine $(n=6)$} \\
\hline & Day 0 & $14^{\text {th }}$ day & $28^{\text {th }}$ day & F-Value & Day 0 & $14^{\text {th }}$ day & $28^{\text {th }}$ day & F-Value \\
\hline$\overline{\mathrm{BUN}}(\mathrm{mg} / \mathrm{dL})$ & $52.39 \pm 9.29$ & $36.50 \pm 5.30$ & $25.80 \pm 2.80$ & $3.48^{\mathrm{NS}}$ & $55.50 \pm 7.10^{\mathrm{a}}$ & $37.10 \pm 2.25^{\mathrm{ab}}$ & $29.33 \pm 6.96^{b}$ & $5.22 *$ \\
\hline $\mathrm{Cr}(\mathrm{mg} / \mathrm{dL})$ & $1.42 \pm 0.48$ & $0.99 \pm 0.22$ & $0.69 \pm 0.07$ & $1.06 \mathrm{NS}$ & $1.54 \pm 0.38$ & $1.78 \pm 0.49$ & $1.05 \pm 0.16$ & 0.45 NS \\
\hline $\mathrm{TP}(\mathrm{g} / \mathrm{dL})$ & $6.85 \pm 0.26$ & $6.80 \pm 0.55$ & $6.92 \pm 0.29$ & 0.92 NS & $6.98 \pm 0.32$ & $6.61 \pm 0.16$ & $7.03 \pm 0.06$ & $0.78^{\mathrm{NS}}$ \\
\hline Albumin $(\mathrm{g} / \mathrm{dL})$ & $2.21 \pm 0.13$ & $2.78 \pm 0.25$ & $2.52 \pm 0.11$ & $3.71 \mathrm{NS}$ & $2.21 \pm 0.13$ & $2.43 \pm 0.14$ & $2.56 \pm 0.14$ & $1.32 \mathrm{NS}$ \\
\hline Globulin $(\mathrm{g} / \mathrm{dL})$ & $4.20 \pm 0.49$ & $4.53 \pm 0.49$ & $4.40 \pm 0.28$ & $0.14 \mathrm{NS}$ & $4.76 \pm 0.32$ & $4.18 \pm 0.25$ & $4.46 \pm 0.20$ & $1.14 \mathrm{NS}$ \\
\hline Albumin:Globulin & $0.59 \pm 0.13$ & $0.57 \pm 0.13$ & $0.58 \pm 0.05$ & $0.04^{\mathrm{NS}}$ & $0.47 \pm 0.48$ & $0.60 \pm 0.7$ & $0.57 \pm 0.05$ & $1.22 \mathrm{NS}$ \\
\hline ALT (IU/L) & $252.00 \pm 38.80^{\mathrm{a}}$ & $127.50 \pm 43.16^{b}$ & $91.40 \pm 33.75^{\mathrm{b}}$ & $4.67 *$ & $74.67 \pm 32.71$ & $68.00 \pm 14.53$ & $266.83 \pm 47.75$ & $14.01 * *$ \\
\hline $\operatorname{ALP}(\mathrm{IU} / \mathrm{L})$ & $387.29 \pm 60.16$ & $330.83 \pm 72.9$ & $\begin{array}{l}473.40 \pm \\
150.53\end{array}$ & $0.54^{\mathrm{NS}}$ & $\begin{array}{l}166.17 .0 \pm \\
29.13\end{array}$ & $\begin{array}{l}308.50 \pm \\
79.08\end{array}$ & $563 \pm 85.32$ & $8.40 * *$ \\
\hline T.bilirubin (IU/L) & $2.33 \pm 0.34^{\mathrm{a}}$ & $0.76 \pm 0.18^{\mathrm{b}}$ & $0.56 \pm 0.08^{\mathrm{b}}$ & $14.2^{*}$ & $1.46 \pm 0.29$ & $0.88 \pm 0.20$ & $0.62 \pm 0.14$ & $2.62^{\mathrm{NS}}$ \\
\hline D.bilirubin (IU/L) & $1.74 \pm 0.20^{\mathrm{a}}$ & $0.54 \pm 0.14^{\mathrm{b}}$ & $0.48 \pm 0.05^{\mathrm{b}}$ & $19.53^{*}$ & $1.45 \pm 0.21$ & $0.87 \pm 0.26$ & $0.65 \pm 0.04$ & $2.75 \mathrm{NS}$ \\
\hline
\end{tabular}

Mean bearing same manuscript in the row do not differ significantly; ** - Statistically highly significant $(\mathrm{P} \leq 0.01)$ * Statisticallysignificant $(\mathrm{P}>0.05)^{\mathrm{NS}}-$ Non significant.

of opsonized RBC (Piek, 2011) or decreased production of antibodies (Barker et al., 1992) by reducing lymphocytes in the circulation pool (Dowling, 1995).

Table 4: Efficacy of different treatments on haemogram in secondary IMHA (Babesia gibsoni) (Comparison in between groups of treatment) $(\mathrm{n}=13)$

\begin{tabular}{lll}
\hline Parameters & $\begin{array}{l}\text { t-test value between } \\
\text { group (Day14) }\end{array}$ & $\begin{array}{l}\text { t-test value between } \\
\text { group (Day28) }\end{array}$ \\
\hline $\mathrm{Hb}(\mathrm{g} / \mathrm{dL})$ & $2.16^{\mathrm{NS}}$ & $7.05^{* *}$ \\
$\mathrm{RBC}(\mathrm{mill} / \mu \mathrm{L})$ & $0.45^{\mathrm{NS}}$ & $1.37^{*}$ \\
$\mathrm{HCT}(\%)$ & $1.04^{\mathrm{NS}}$ & $2.08^{\mathrm{NS}}$ \\
$\mathrm{MCV}(\mathrm{fL})$ & $1.02^{\mathrm{NS}}$ & $1.74^{\mathrm{NS}}$ \\
$\mathrm{MCHC}(\mathrm{g} / \mathrm{dL})$ & $0.10^{\mathrm{NS}}$ & $0.37^{\mathrm{NS}}$ \\
$\mathrm{MCH}(\mathrm{pg})$ & $0.60^{\mathrm{NS}}$ & $3.04^{\mathrm{NS}}$ \\
\hline
\end{tabular}

NS -Non significant, ** - Statistically highly significant $(\mathrm{P} \leq 0.01)$, * - Statistically significant $(\mathrm{P}<0.05)$.

The mean of BUN on $14^{\text {th }}$ day of treatment was significantly lower in prednisolone treated group compared to prednisolone combination with azathioprine group. Mean of ALT and ALP was significantly higher in prednisolone + azathioprine group as compared to prednisolone treated group on $28^{\text {th }}$ day post treatment. Mean activities of ALP was significantly higher in prednisolone group as compared to prednisolone + azathioprine treated group on $14^{\text {th }}$ day post treatment. Weinkle et al. (2005) and Mason et al. (2003) stated good response or an improved overall prognosis in patients receiving the drug. Rinkardt and Kruth (1996), Whitley and Day (2011) reported immunosuppressive action was delayed for several weeks after beginning therapy. The idiosyncratic occurrence of myelosuppression and hepatotoxicity can present a monitoring challenge in IMHA dogs whose alkaline phosphatase is likely increased because of glucocorticoid therapy. Wang et al. (2013) reported adverse events including significantly increased ALT, vomiting and diarrhoea in dogs treated with azathioprine.

Table 5: Efficacy of different treatments on leucogram and coagulation profile in secondary IMHA (Babesia gibsoni) (Comparison in between groups of treatment)

\begin{tabular}{lll}
\hline Parameters & $\begin{array}{l}\text { t-test value between } \\
\text { group (Day14) }\end{array}$ & $\begin{array}{l}\text { t-test value between } \\
\text { group (Day28) }\end{array}$ \\
WBC $(/ \mu \mathrm{L})$ & $1.21^{\mathrm{NS}}$ & $2.14^{\mathrm{NS}}$ \\
Neutrophil $(\%)$ & $0.16^{\mathrm{NS}}$ & $0.40^{\mathrm{NS}}$ \\
Lymphocyte $(\%)$ & $0.88^{\mathrm{NS}}$ & $0.37^{\mathrm{NS}}$ \\
Monocyte $(\%)$ & $1.91^{\mathrm{NS}}$ & $0.95^{\mathrm{NS}}$ \\
Eosinophil $(\%)$ & $3.04^{*}$ & $1.29^{\mathrm{NS}}$ \\
Platelet $\left(10^{3} / \mathrm{cmm}\right)$ & $0.28^{\mathrm{NS}}$ & $1.28^{\mathrm{NS}}$ \\
PT $(\mathrm{sec})$ & $0.36^{\mathrm{NS}}$ & $0.98^{\mathrm{NS}}$ \\
APTT $(\mathrm{sec})$ & $1.02^{\mathrm{NS}}$ & $0.46^{\mathrm{NS}}$ \\
\hline
\end{tabular}

NS - Non significant, * - Statistically significant $(\mathrm{P}<0.05)$. 
Table 6: Efficacy of different treatments on serum biochemistry in secondary IMHA (Babesia gibsoni) (Comparison in between groups of treatment)

\begin{tabular}{lll}
\hline Parameters & $\begin{array}{l}\text { t-test value between } \\
\text { group (Day 14) }\end{array}$ & $\begin{array}{l}\text { t-test value between } \\
\text { group (Day 28) }\end{array}$ \\
\hline BUN(mg/dL) & $0.32^{*}$ & $0.56^{\mathrm{NS}}$ \\
$\mathrm{Cr}(\mathrm{mg} / \mathrm{dL})$ & $1.40^{\mathrm{NS}}$ & $2.29^{\mathrm{NS}}$ \\
$\mathrm{TP}(\mathrm{g} / \mathrm{dL})$ & $0.75^{\mathrm{NS}}$ & $0.28^{\mathrm{NS}}$ \\
Albumin $(\mathrm{g} / \mathrm{dL})$ & $1.25^{\mathrm{NS}}$ & $0.24^{\mathrm{NS}}$ \\
Globulin $(\mathrm{g} / \mathrm{dL})$ & $0.62^{\mathrm{NS}}$ & $0.16^{\mathrm{NS}}$ \\
Albumin: Globulin & $0.16^{\mathrm{NS}}$ & $0.06^{\mathrm{NS}}$ \\
ALT (IU/L) & $1.00^{\mathrm{NS}}$ & $3.14^{* *}$ \\
ALP (IU/L) & $2.69^{*}$ & $4.71^{* *}$ \\
T.bilirubin (IU/L) & $0.42^{\mathrm{NS}}$ & $0.36^{\mathrm{NS}}$ \\
D.bilirubin (IU/L) & $1.07^{\mathrm{NS}}$ & $2.20^{\mathrm{NS}}$ \\
\hline
\end{tabular}

NS - Non significant, $* *$ - Statistically highly significant $(\mathrm{P} \leq 0.01)$, * - Statistically significant $(\mathrm{P}<0.05)$.

\section{Treatment outcome/response}

Out of seven dogs received prednisolone treatment ( $\mathrm{P}$ Protocol) one dog died on $1^{\text {st }}$ week and remaining six dogs recovered after four weeks of treatment.

Out of six dogs received prednisolone + azathioprine treatment (AP Protocol) two dogs died on $1^{\text {st }}$ week and remaining four dogs recovered after four weeks of treatment.

In the present study, mortality in secondary IMHA was 23.1 per cent. In secondary IMHA prednisolone and prednisolone + azathioprine treatment group mortality was 14.3 per cent and 33.33 per cent respectively.

The mortality in the present study was 23.1 per cent (secondary IMHA), similar rate of mortality (20 to 33 per cent) was observed by Jackson and Kruth (1985), Klag et al. (1993) and Scott-Moncrieff et al. (2001). Mortality is mostly in the first 2 weeks of diagnsosis (Piek, 2011). Similar observation was recorded in present study. Mortality in IMHA dogs might be due to thromboembolism (Scott - Moncrieff et al., 2001), tissue hypoxia and subsequent necrosis due to severe anaemia, liver and kidney failure, inflammation and DIC (McCanus and Craig, 2001 and Piek, 2011). Necropsy could not be performed in the present study due to the animal collapsed in the owner's house, the exact reason for death was not identified.

\section{CONCLUSION}

The anaemic dogs brought with clinical signs such as pale or icteric mucous membranes were screened for IMHA by saline agglutination and spherocyte count and confirmed by flow cytometry. The positive cases were further subjected to haematology, biochemistry, coagulation profile, MAT and polymerase chain reaction (PCR) for the diagnosis of underlying secondary causes like Babesia spp, Ehrlichia canis and Leptospira spp (secondary IMHA). Thirteen cases were seconday IMHA and Immunosuppressive therapy with prednisolone and prednisolone in combination with azathioprine and specific therapy of etiological agent with supportive therapy was used. Significant increase in $\mathrm{Hb}$, PCV, RBC and thrombocyte count, significant decrease in leucocyte, neutrophil, monocyte and total protein and significant increase in ALT activity was recorded after therapy. Prednisolone was found to be effective in the management of secondary IMHA than prednisolone combined with azathioprine.

\section{REFERENCES}

Balch, A. and Mackin, A. 2007. Canine immune- mediated hemolytic anemia: pathophiosology, clinical sign, and diagnosis. Compend. Contin. Educ. Vet., 29(4): 217-225.

Barker, R.N., Gruffydd-Jones, T.J., Stokes, C.R. and Bourne, F.J. 1992. Autoimmune haemolysis in the dog: relationship between anaemia and the levels of red blood cell bound immunoglobulins and complement complement measured by an enzyme-linked antiglobulin test. Vet. Immunol. Immunopathol., 34: 1-20.

Burgess, K., Moore, A. and Rand, W. 2000. Treatment of immunemediated hemolytic anemia in dogs with Cyclophosphamide. J. Vet. Intern. Med., 14(4): 456-462.

Dowling, P.M. 1995. Immunosuppressive drug therapy. Can. Vet. J., 36(12): 781-783.

Giger, U. 2005.Regenerative anemias caused by blood loss or hemolysis. In: Ettinger SJ, Feldman EC (eds): Textbook of Veterinary Internal Medicine, $6^{\text {th }}$ Edn,. St Louis, Saunders, pp. 1886-1907.

Jackson, M.L. and Kruth, S.A. 1985. Immune-mediated hemolytic anemia and thrombocytopenia in dogs: a retrospective study of 55 cases diagnosed from 1969 through 1983 at the western college of veterinary medicine. Can. Vet.J. Res., 26(8): 245-250.

Klag, A., Giger, U. and Shofer, F. 1993. Idiopathic immunemediated hemolytic anemia in dogs: 42 cases (1986- 1990). J. Am. Vet. Med. Assoc., 202 (5): 783-788. 
Kledmanee, K., Suwanpakdee, S., Krajangwong, S., Chatsiriwech, J., Sukasai, P., Suwannachat, P.,Sariya, L., Buddhirongawatr, R., Charoonrut, P. and Chaichoun, K. 2009. Development of multiplex polymerase chain reaction for detection of Ehrlichia canis, Babesia spp. and Hepatazoan canis in canine blood. Southeast Asian T. Med. Public Health, 40(1): 35-39.

Kucinskiene, G., Schuberth, H.J., Leibold, W.J. and Pieskus, J. 2005. Flow cytometric evaluation of bound $\operatorname{IgG}$ on erythrocytes of anaemic dogs. Vet. J., 169: 303-307.

Mason, N., Duval, D., Shofer, F.S. and Giger, U. 2003. Cyclophosphamide exerts no beneficial effect over prednisone alone in the initial treatment of acute immune mediated hemolytic anemia in dogs: a randomized controlled clinical trial. J. Vet. Intern. Med., 17(2): 206-212.

McAlees, T.J. 2010. Immune-mediated hemolytic anaemia in 110 dogs in Victoria, Australia. Aust. Vet. J., 88: 25-28.

McManus, P. and Craig, L.2001. Correlation between leukocytosis and necropsy finding in dogs with immune mediated hemolytic anemia: 34 cases (1994-1999). JAVMA., 218(8): 1308-1313.

Piek, C.J. 2011. Canine idiopathic immune-mediated hemolytic anemia: a review with recommendations for future research. Vet. Q., 31: 129-141.
Rinkardt, N.E. and Kruth, S.A. 1996. Azathioprine-induced bone marrow toxicity in four dogs. Can. Vet. J., 37: 612-613.

Scott-Moncrieff, J.C., Treadwell, N.G. and McCullough, S.M. 2001. Hemostatic abnormalities in dogs with primary immune-mediated hemolytic anemia. J. Am. Anim. Hosp. Assoc., 37: 220-227.

Suzuki, K., Wakabayashi, H., Takahash, M., Fukushima, K., Yabuki, K. and Endo, Y. 2007. A possible treatment strategy and clinical factors to estimate the treatment response inBabesia gibsoni infection. J. Vet. Med. Sci., 69(5): 563-568.

Wang, A., Smith, J.R. and Creevy, K.E. 2013. Treatment of canine idiopathic immune mediated haemolytic anaemia with mycophenolate mofetil and glucocorticoids: 30 cases (2007 to 2011). J. Small. Anim. Pract., 54(8): 399-404.

Weinkle, T.K., Center, S.A., Randolph, J.F., Warner, K.L., Barr, S.C. and Erb, H.N. 2005. Evaluation of prognostic factors, survival rates, and treatment protocols for immune-mediated hemolytic anemia in dogs: 151 cases (1993-2002). J. Am. Vet. Med. Assoc., 226: 1869-1880.

Whitley, N.T. and Day, M.J. 2011. Immunomodulatory drugs and their application to the management of canine immunemediated disease. J. Small. Anim. Pract., 52(2): 70-85. 
